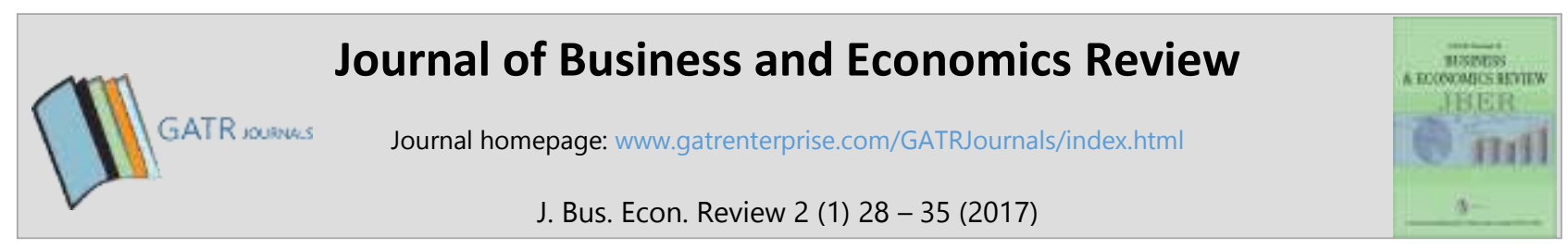

\title{
Negotiation with Patriarchy in Women's Lives: A Case Study in a Malaysian Public University
}

\author{
Azman Azwan Azmawati ${ }^{*}$, Noraida Endut ${ }^{2}$, Intan Hashimah Mohd Hashim ${ }^{3}$, Nor Hafizah \\ Selamat $^{4}$ and Kelvin Ying ${ }^{5}$ \\ 1,2,3,4,5 Centre for Research on Women and Gender (KANITA), Universiti Sains Malaysia, Penang, Malaysia
}

\begin{abstract}
Objective - While women make up almost $65 \%$ of undergraduates in public universities in Malaysia, only in the last three years their labour force participation rates have gone beyond the $50 \%$ mark. In addition, women form less than $20 \%$ of the legislature and Cabinet of Ministers in Malaysia. What pushes women in their achievements in education and what factors pull them back in other areas? How do patriarchal gender norms underpin their ability and decisions in life's choices and how have they understood and negotiated these norms? This paper aims to explore these questions through narratives of women in a public university.

Methodology/Technique - The paper is based on Focus Group Discussions (FGDs) with 12 women who are staff and postgraduate students of the university. The respondents were divided into two groups: one consisting of the university's academic and administrative staff and the other postgraduate students. Separate discussions were conducted for each group. The discussions were transcribed and analysed.

Findings - Findings show that women have confidence in their ability to contribute effectively and in the same manner as men in different spheres of their lives such as work, home and community. However, often they have had to negotiate their ways around various beliefs, practices and norms about the superiority of men in society.
\end{abstract}

Novelty - The study researches factors that affects woman achievements in life.

Type of Paper: Empirical

Keywords: Gender roles and Characteristic, Masculinity, Patriarchy

JEL Classification: J16, J18.

\section{Introduction}

Women have been shown to have to continuously negotiate with the patriarchal elements of their sociocultural spaces to gain increased and more fluid movement between their private and public spaces of lives. Women's gender roles and expectations are highly ordered by cultural contexts, which in many cases continue to be patriarchal. Patriarchy is an indispensable concept in analyzing gender equality "as it captures the depths, pervasiveness, and interconnectedness of different aspects of women's subordination within the

* Paper Info: Received: January 2, 2017

Accepted: February 27, 2017

* Corresponding author:

E-mail: azwan@usm.my

Affiliation: Centre for Research on Women and Gender (KANITA), Universiti Sains Malaysia, Malaysia. 
household, family, and society (Walby, 1990). The forces of patriarchy form fundamental impediments to women's ability to participate in livelihood activities because the concept of "chastity" or honor in patriarchal understanding often severely restrict women's mobility and cast judgment on their morality and reputation (see e.g. Ahmad and Naimat, 2011). Thus, patriarchy, and how women negotiate around it, is a very important context to investigate to see how it (still) affects women's ability to achieve gender equality and justice.

Gender equality and non-discrimination have been constitutionally guaranteed in Malaysia since 2001 . Malaysia also acceded to the Convention on the Elimination of All Forms of Discrimination (CEDAW) in 1995, which legally obligates it to "respect, protect, promote and fulfill" women's rights to nondiscrimination and to gender equality (Recommendation No. 25 of CEDAW). Gender equality and nondiscrimination further mean the guarantee of equality of access, opportunity, and results or outcome for women and men. The guarantee of this substantive equality must be observed in a spectrum of women's lives, spanning both the public and private spheres. Thus, it covers the contexts of women's education, work, health, economic well-being, political participation and so on.

Malaysia's Global Gender Gap Index of 2016 shows that while Malaysian women fair quite well in education and health, the gaps between women and men in the area of economic and political empowerment are noticeably wide. Malaysia ranked 80 out of 144 countries in closing the gap for economic participation and opportunity and 134 for political empowerment (World Economic Forum, 2016). Malaysia's score for political empowerment shows a very high imparity, at 0.051 (where 1 indicates the highest parity and 0 lowest parity). Malaysia's performance in narrowing the gender gap in the last five years has not shown very significant improvement based on the Global Gender Gap Index reports. According to the Planning, Research and Policy Coordination Division of Ministry of Higher Education (MOHE), in 2016, the ratio of male to female university students is 1:1.63. Female students consist of $62.01 \%(335,254$ out of 540,638$)$ of total enrolment in universities in Malaysia (Ministry of Education Malaysia, 2016). However, in 2015, the female labor force participation rate in Malaysia stood at 54.1\%. Between 1990 and 2013 the female labor force participation rates slowly moved between $43 \%$ and 46\% (Department of Statistics Malaysia, 2015). The 2016 Global Gender Gap Index reported that Malaysia scored 0.650 (and ranked at 104) for the labor force participation rate, which indicates relatively high imparity.

It is important to understand why as Malaysian women over-achieve in education, their labor force participation rate and economic empowerment continue to show wide gaps compared to men. How do women describe and explain their positions in their livelihood activities and what sociocultural contexts are at play in their lives? Is patriarchy alive in the Malaysian context and how have women deal with the effects of patriarchy on their socioeconomic wellbeing? These are a few of the questions that form the basis for exploring women's views and narratives in the study on which this paper is based.

Hence, this paper aims to explore two main issues through the narratives of women in a public university:

i. the factors that pushed women in their achievements in education and the factors that pull them back in other areas and;

ii. the way that patriarchal gender norms underpin their ability and decisions in life's choices as well as how have they understood and negotiated these norms

\section{Literature Review}

\subsection{Sex, Gender and Culture}

Despite many who use the terms gender and sex interchangeably, they have distinct meanings. Sex is a designation based on biology where a person is considered male or female based on external genitalia of penis and vagina, and internal sex organs of ovaries and uterus in the female, prostate in the male. Gender, on the other hand, is socially and psychologically constructed. The term gender refers to identities, roles, 
activities, feelings and so on that society associate with being female or male. Since societies are not homogenous, the meaning of gender has come to depend on a society's particular values, beliefs and preferred ways of organizing collective life. In this context, gender is thus, learned (Wood, 2001).

Socially endorsed views of feminity and masculinity are taught to individuals through a variety of cultural means. For example, to be masculine is to be strong, ambitious, successful, rational and emotionally controlled (House, Dallinger, \& Kilgallen, 1998). To be feminine, on the other hand, is to be physically attractive, deferential, emotionally expressive, nurturing and concerned with people and relationships. 'Real women' must still look good while caring for her family, adoring of their children and being a homemaker. These basic prescriptions mainly remain constant (Greenfield, 1997; Kerr, 1999; Spence \& Buckner, 2000).

Unequal power between male and female arises from gender inequalities. 'Gender norms' assign specific entitlements and responsibilities to women and men such as women might be expected to take on caring or domestic duties and remain close to home even though they have careers. Men, on the other hand, may be expected to be the main breadwinner and work outside the home with greater freedom to move around in public places. If gender inequality persists, this will have implications for women's capacity to benefit from all aspect of lives (Wood, 2001).

Gender stereotypes are the products of cultures. The idea of cultural difference in gender roles has been supported by numerous studies (Basow, 1984; Chia, Moore, Lam, Chuang, \& Cheng, 1994; Lara-Cantu \& Navarro-Arias, 1987; Moore, 1999; Novakovic \& Kidd, 1988; Ward \& Sethi, 1986; Williams, Satterwhite, \& Best, 1999).

\subsection{Patriarchy}

Patriarchy is crucial to be studied because of its negative impact on women and how stereotyping women is its result. The patriarchal system hinders women from reaching their potential. Patriarchy in this study refers to an ideology that raises men to positions of superiority and to recognize men's importance compared to women. This, in turn, disregards women's ability, potential, qualifications, skills and other aspects of women's lives.

Patriarchy literally means 'rule by fathers'. It generally refers to systems of ideology, social structures, practices which are created by men that reflect the values, priorities, and views of men, as a group.

"Patriarchy in its wider definition means the manifestation and institutionalisation of male dominance over women and children in the family and the extension of male dominance over women in society, in general, it implies that men hold power in all-important institutions of society and that women are deprived of access to such power. It does not imply that women are wither totally powerless or totally deprived of rights, influence and resources.” (Wood, 2001)

Under the patriarchal system, the norms that require women to be submissive are reproduced by the ideology that women are psychologically and physically weak.

Feminist theory defines patriarchy as an unjust social system that enforces gender roles and is oppressive to both men and women. It often includes any social mechanisms that evoke male dominance over women. Yifei (2011) debated several theories and origins of patriarchy while attempting to explain "the how and why questions" of patriarchy within the contexts social norms in China. According to him, in feminism, while 'patriarchy' is a commonly used term, it nevertheless lacks a clear-cut meaning. Weber (2004) used the term 'patriarchy' to describe a social system where the male uses his head-of-household status in the family to control the female. Many later researchers who adhered to Weber's logic have regarded patriarchy as a mechanism of inequality consisting of two intersecting dimensions of gender and generation. (Yifei, 2011).

In the late 1990s, Denis Kandiyoti coined the term "patriarchal bargain". This describes a strategy women use to gain some life advantages in situations where their lives are being regulated by patriarchal norms. In this strategy or tactic, women choose to accommodate and perhaps support patriarchal practices 
that have been detrimental to women, in order to obtain or maximize their own options and standing in society. Wade (2011) summarizes patriarchal bargain and contextualize it to more contemporary situation, as

"a decision to accept gender rules that disadvantage women in exchange for whatever power one can wrest from the system. It is an individual strategy designed to manipulate the system to one's best advantage, but one that leaves the system itself intact."

In many circumstances women find themselves having to choose their battles in advancing their positions in society. Thus, women would conform to strict requirement about what clothes they can wear, how they should behave and which spaces they can enter in order for them to be able to claim the rights to move between the private and public spheres of their lives. These contexts of bargaining for Malaysian educated women will be part of the premise of this paper.

\section{Research Design and Methodology}

The study uses a qualitative approach to research in order to analyze the in-depth information of the experiences of individuals (Nieuwenhuis, 2007). The paper is based on Focus Group Discussions (FGDs) with 12 women who are staff and postgraduate students of a public university. The respondents were divided into two groups: one consisting of administrative and academic staff and the other of postgraduate students. The inclusion criteria for the participants in the first group included: (1) permanent staff of the university; (2) 30-50 years old and; (3) able to speak English or Malay. The inclusion criteria for the participants in the second group included: (1) postgraduate students of the university; (2) 20-30 years old and; (3) able to speak English or Malay. Separate discussions were conducted for each group. Each group consisted of between five to seven participants. Each discussion session took between one to two-and-a-half hours.

In each session, a brief introduction of the research and the process of FGD were explained to the participants by the chairperson. The voluntary nature of respondents' participation and the requirement for their consent to participate in the study were also discussed. Consent forms were given at this point and participants were asked to read and sign the form if they agreed to proceed.

Each FGD session was led by either the principal investigator or a co-researcher and proceedings were electronically recorded (with participants' consent) for the purpose of data management. Throughout the FGD, participants shared their personal ideas and experiences on physical appearance, traits and behaviors of both sexes, and gender roles. Each participant was given an honorarium at the end of the FGD session. Narratives were transcribed and coded according to the emerging categories of meanings.

The mean age of participants is 34.3 years $(\mathrm{SD}=10.3)$. Participants' self-reported ethnicities include Malay ( $n=5)$, Chinese $(n=3)$, Indian $(n=3)$, and Punjabi $(n=1)$.

\section{Findings}

For the purpose of this paper, the narratives of and exchanges with the participants yield qualitative data that can be thematically divided into 1) women's consciousness and identification of patriarchy and 2) women's negotiation with and around patriarchy.

\subsection{Consciousness and identification of patriarchal and gender norms}

The study reveals that the participants tend to identify with the pervasive gender norms and do not feel that the construction of gender roles and the prescription of the gender division of labor to be problematic. The women feel that the normative attributes generally pinned to women and men are correct and logical. Thus, they believe that men have a tendency to think in a simple way, talk less, are more action-oriented and have very practical outlook compared to women: 
'... women are more emotional, even at very small issues. At times, they are not able to control themselves...'

'In communication, women like to beat around the bush or simply say don't know or it depends on you (to a man). Men will say I don't want, I say I don't want.'

Despite their relatively high education background, and thus, their potential to advance in their work and livelihood activities, perhaps on the same level as their male family members or colleagues, many participants still subscribe to the traditional notion of gender division of labor. A woman said:

'Men, they go out, the women stay at home. Women are mostly the one to nurture the children and take care of the family. The men actually go out to find food and take care of the family. Then, women take care of the children and manage the family.'

She has supports from the other women in this view:

'I mean, men to a certain extent can do the nurturing job but women are better in that. At nurturing, patience and the whole dynamics in the emotional way, there is a difference between men and women.'

'There are some things females are better off with as the term is fitrah [nature] in Islam. We are more emotional and very caring. For men, it is more about responsibilities. Although men are not at home to cook and take care of the children, men know their responsibilities - to earn and protect the family.'

Women's acceptance of the gender stereotypes and gender division of labor is not only obvious in relation to issues in the domestic sphere. It permeates through to work situation as well. When given a scenario about a staff at work being terminated and asked about the possible different responses if the staff being terminated is a female or male, a respondent said:

'Initially, a woman will be upset, angry and discuss with her workmates. She will not confront her superior directly without discussing with others first. A man will directly go to his superior and ask what is the problem and why the drastic action.'

Another respondent said:

'Men like to confront and have the tendency to be aggressive. Women will not be confrontational.'

\subsection{Negotiating with and around patriarchy}

The participants observe that women around them do consciously or unconsciously strategise their lives around the patriarchal social norms in order for them to gain access to certain rights or life's advantages. Women who have higher education and better jobs than their husbands may make efforts to show deference to the latter in the homes to gain society's approval of their positions in the public domain. One respondent said:

"I have friends [in this university] who earning more than their husbands. Their husbands are working but are lower qualified [than them]. But I think they still [treat] their husbands as the head of family" 
Another said:

"[Because in our religion] the man is the head of the household, so although we earn more, men can still be the head of the family"

One respondent shared her own similar situation:

"I think we both are [leaders of our family]. But I let my husband be [the clear leader]. I give my opinions but the final word will be [his]. Because they listen to him more."

To facilitate their continuous mobility between the public and private spaces of their lives, women are willing to accept certain restriction:

"So, if u start to go [travel] by yourself, you might face with certain challenges. So you go with your husband to avoid [these things].

In the end analysis, women feel that sticking to many of the prescribed gender norms and practices will offer them better survival in society:

"Both [women and men] have their roles to protect the family but in different ways. For example, cooking, taking care of the children, taking care of the husband's well-being and providing are women's responsibilities while men, earn - both are survival strategies."

\subsection{A changing attitude?}

There is a small indication of openness to change amongst participants when talking about a situation of role-reversal in the form of the issue of stay-at-home husbands. There were some hesitations at first:

"In terms of cultural, it is normal and acceptable for the guy to work and feed the family and the wife uses his money. And it is not normal for husband to use the wife's money."

"Maybe people will question this arrangement. And this will have an impact on his self-esteem. Maybe he will be thinking along this line - am I not capable of providing for my family (earning), I am just staying at home and use my wife's earnings."

However, a few respondents feel that the case can be a workable arrangement:

"He can stay at home on condition that he has income, which means he has a business running, not depending on the women to give him money."

"I think this is ok but on condition that the male's self-esteem will not be decreased because of this. Because for men, they may have it in their heart that ' $I$ have to be responsible to take care of this family with my own earned money and women should stay at home"”.

"But what I feel is that there is one situation [where] the girl earns money, she has sufficient money for the family, the guy [can] stay at home and take care of the children.... I think in this situation it is ok, because as long as the father stays at home, he is doing all the duties in the house, and the woman is going out and doing her duty as "what a husband does" [normally], it is the same thing." 
Participants may, thus, be able to rethink the gender context of their lives to accept a situation that allow for a more equal division of labor.

\section{Conclusion}

Based on the findings of this study, it can be argued that patriarchy still remains a lived reality for many women in Malaysia. The context of patriarchy for women spans their private and public lives and have continued to order their lives despite their advancement in spheres such as education and health. It is not an easy task for women to challenge patriarchy, but this has to be done if women are to reach their full potential and aspire to those positions presently dominated by men.

Women have confidence in their ability to contribute effectively and in the same manner as men in different spheres of their lives such as work, home, and community. However, often they have had to negotiate their way around various beliefs, practices, and norms about the superiority of men in society. The women have different views about areas of gender division, of labor and on how these factors have affected them. When given spaces to consider more equitable gender relations by creating role-reversal cases, women may be able to claim these spaces and subscribe to possible changing norms about the relationship between women and men in society. If these spaces are widely provided for both women and men, patriarchy may be able to be challenged more effectively.

\section{Note of Appreciation}

The authors would like to record their gratitude to the Universiti Sains Malaysia (USM) for funding the research project on which this article is based.

\section{References}

Ahmad, H. M. and Naimat, S. (2011). Networking and women entrepreneurs: Beyond patriarchal traditions. African Journal of Business Management, 5(14), 5784-5791.

Basow, S. A. (1984). Cultural variations in sex-typing. Sex Roles, 10(7-8), 577-585.

Chia, R. C., Moore, J. L., Lam, K. N., Chuang, C. J., \& Cheng, B. S. (1994). Cultural differences in gender role attitudes between Chinese and American students. Sex roles, 31(1-2), 23-30.

Department of Statistics Malaysia. (2015). Labour Force Survey Report Malaysia 2015[Press release]. Retrieved from: https://www.dosm.gov.my/v1/index.php?r=column/pdfPrev\&id=TFVqZ2NtWW9iNlJBV0pTQnZUUzBEZz09

Greenfield, T. A. (1997). Gender- and grade- level differences in science interest and participation. Science education, 81(3), 259-276.

House, A., Dallinger, J. M., \& Kilgallen, D. L. (1998). Androgyny and rhetorical sensitivity: The connection of gender and communicator style. Communication Reports, 11(1), 11-20.

Kandiyoti, D. (1988). 'Bargaining with Patriarchy'.Gender and Society, 2(3), 274-290.

Kerr, B. M. (1999). Religious Life for Women, C. 1100-c. 1350: Fontevraud in England. Oxford University Press on Demand.

Lara-Cantu, M. A., \& Navarro-Arias, R. (1987). Self-descriptions of Mexican college studentsin response to the Bem Sex Role Inventory and other sex role items. Journal of Cross-CulturalPsychology, 18(3), 331-344.

Ministry of Education Malaysia. (2016). Quick Facts 2016 Malaysia Educational Statistics. Retrieved from:http://www.moe.gov.my/index.php/en/media/penerbitan/terbitan/buku-informasi/book/10/1?page=2

Moore, H. (1999). Whatever happened to women and men? Gender and other crises inanthropology (pp. 151-171). Polity Press.

Nieuwenhuis, J. (2007). Qualitative research designs and data gathering techniques. First steps in research, 69-97.

Novakovic, T., \& Kidd, A. H. (1988). Gender self-concepts in the USA and Yugoslavia. Psychological Reports, 62(2), 611-617.

Spence, J. T., \& Buckner, C. E. (2000). Instrumental and expressive traits, trait stereotypes, and sexist attitudes: What do they signify?. Psychology of women quarterly, 24(1), 44-53. 
Wade, L. (2011, May 22). Serena Williams' Patriarchal Bargain. The society pages. Retrieved from: https://thesocietypages.org/socimages/2011/05/22/women-damned-if-you-do-damned-if-you-dont/

Walby, S. (1990). From Private to Public Patriarchy, in Theorizing Patriarchy. Basil Blackwell Ltd.

Ward, C., \& Sethi, R. R. (1986). Cross-cultural validation of the Bem Sex Role InventoryMalaysianand South Indian research. Journal of Cross-Cultural Psychology, 17(3), 300-314.

Weber, L. (2004). A conceptual framework for understanding race, class, gender, and sexuality. In S. N. HesseBiber, \& M. L. Yaiser (Eds.), Feminist perspectives on social research (pp. 121-139). New York, NY: Oxford University Press.

Williams, J. E., Satterwhite, R. C., \& Best, D. L. (1999). Pancultural gender stereotypes revisited: The five factor model. Sex roles, 40(7-8), 513-525.

Wood, J. T. (2001). Gendered lives: Communication, gender and culture. Belmont, CA: Wadsworth.

World Economic Forum (WEF). (2016). The Global Gender Gap Report 2016.Retrieved from http://reports.weforum.org/global-gender-gap-report-2016/

Yifei, S. (2011). China in the 'Post-Patriarchal Era' Changes in the Power Relationships in Urban Households and an Analysis of the Course of Gender Inequality in Society. Chinese Sociology \& Anthropology, 43(4), 5-23. 